ABSTRACT BOOK

\title{
INTERNATIONAL PUBLIC HEALTH CONFERENCE «PUBLIC HEALTH IN UKRAINE - MODERN CHALLENGES AND DEVELOPING PROSPECTS", 22-23 APRIL 2021, SUMY, UKRAINE
}

\section{SCIENTIFIC-ORGANIZATIONAL CONFERENCE COMMITTEE}

\section{HEAD}

Vladyslav A. Smiianov - Doctor of Medical Sciences, Professor, Head of Public Health Department, Medical institute, SSU

\section{DEPUTY HEAD}

Lesia A. Rudenko - Scientific editor, moderator of project of ALUNA publisher

\section{SECRETARY}

Viktoria O. Yasenok - Associate professor of Public Health Department, Medical institute, SSU

\section{COMMITTEE MEMBERS:}

1. Yurochko P. Tetiana - Head of the Department "School of Public Health", National University of "Kyiv-Mohyla Academy"

2. Ihor V. Hushchuk - Head of Public Health Department, National University of Ostroh Academy

3. Oleksandr Smiyan - Head of the Department of Paediatrics, Medical institute, SSU

4. Lyudmyla Prystupa - Head of Internal Medicine Department of Postgraduation Education, Medical institute, SSU

5. Yuriy Lakhtin - Head of Dentistry Department, Medical institute, SSU

6. Bartosz Guterman - Head of Subscription Department of ALUNA publisher, Coordinator of Association of Polish Health Resorts` Patients project

7. Viktor Orlovski - Head of Family Medicine and Dermatovenerology Department, Medical institute, SSU

8. Oleksandra M. Berhylevych - Professor of Public Health Department, Medical institute, SSU 


\section{DISTINGUISHED PARTICIPANTS AND COLLEAGUES!}

It is my privilege to welcome all of you to the Conference, organized with Sumy State University support! On this occasion I would like to express my sincere and grateful thanks to the editorial board of "Wiadomości Lekarskie" journal which was gave the area for publication of the most outstanding scientific and sociological results of this medical forum.

Turning to our colleagues, I would like to extend my appreciation of your scientific dedication and wish to bring your knowledge to young doctors, medical and public health professionals. I hope that everyone could use the experience, presented in this conference to their practice to ensure the quality and safety of healthcare system throughout the country. The information coming up here will grant participants knowledge to combine their own medical practice and external experience in professional activities.

With this conference, I would like to open a frank and constructive dialogue about key medical and public health problems. This selection of actual and innovative publications will help you in professional medical and public spheres. This conference is a good opportunity for us to explore new facts and problems together, to succeed in cooperation, to share ideas, and to build healthcare and educative systems ready for any challenges.

My final word will be addressed to the young medical scientists. I call on you to take advantage of this conference for absorbing and learning vast experience of elder specialists. This knowledge may help you stimulate your future training and growth as outstanding persons in the medical sphere. For all of us, this conference is aimed to be a great support, given the current conditions of the world healthcare system.

At the conclusion of this letter, I would like to wish you all good health, success and enough strength and patience to overcome any challenges.

\section{Vladyslav A. Smiianov}

Head of Public Health Department,

Medical Institute,

Sumy State University, Sumy, Ukraine 


\title{
CARDIOVASCULAR RISK FACTORS AMONG THE PATIENTS WITH AUTONOMIC DYSFUNCTION AND MILD HYPERTENSION
}

\author{
Yuri A. Ataman, Lina V. Pryimenko, Natalia Y. Volnushkina \\ SUMY STATE UNIVERSITY, SUMY, UKRAINE
}

\begin{abstract}
Introduction: Hypertension remains one of the main non-communicable diseases both in Ukraine and in the world. The problem of autonomic dysfunction in people with high blood pressure deserves special attention given the deteriorating quality of life and prognosis in such patients. Given this, it is important to assess the role of major cardiovascular risk factors in the combination of dysautonomia and hypertension of different severity.

Aim: the aim of the study was to examine the prevalence of cardiovascular risk factors in individuals with symptoms of autonomic dysfunction depending on the level of blood pressure. Materials and methods: A total of 81 patients with hypertension and autonomic dysfunction were examined. Depending on the level of blood pressure, patients were divided into two groups: the first (G1) were 26 people with mild hypertension (1st degree, blood pressure below 160/100 mm Hg), the second (G2) - with grade II and III blood pressure according to 2018 ESC/ESH Guidelines. BP measurements were performed in the office using the oscillometric method with appropriate cuff size determined from arm circumference measurement according to a standardized protocol for measuring BP in the office. The presence of autonomic dysfunction was also determined by standard methodology. The mean values are presented as M (SD), where M is an arithmetic mean, SD is a standard deviation, the comparison of means was carried out using the MannWhitney test method. The comparison of discontinuous variables was carried out using the $x^{2}$ criterion calculation with the Yates correction.

Results: It was found that the groups didn't have significant differences in the prevalence of such risk factors as overweight (G1-30.1\%, G2-32.7\%, $\mathrm{p}=0.932), 0$ besity (G1-38.5\%, $\mathrm{G} 2-49.1 \%, \mathrm{p}=0.511$ ), diabetes mellitus (G1-11.5\%, G2-9.1\%, $\mathrm{p}=0.957)$. And no differences by age (G1-68.7 (14.7), G2-69.2 (14.0), $\mathrm{p}=0.992)$, body mass index (G1-29.1 (6.0), $\mathrm{G} 2-29.7(4.6), \mathrm{p}=0.254)$, office heart rate (G1-72.7 (10.0), G2-73.3 (8.6), $\mathrm{p}=0.841$ ), mean glycaemia (G1-4.7 (0.9), G2-4.9 (1.4), $\mathrm{p}=0.624)$ and prothrombin index (G1-87.5 (8.4), G2-89.5 (8.1), $\mathrm{p}=0.347$ ) were revealed. Only the prevalence of smoking in the second group (56.4\%) was significantly higher than in the first (26.7\%), $\mathrm{p}=0.025 . \mathrm{Both}$ groups expectedly differed in blood pressure, including pulse blood pressure (G1-56.2 (6.8), G2-69.6 (12.1), $\mathrm{p}<0.001)$ and mean blood pressure (G1-109.3 (3.0), G2-121.0 (8.6), $\mathrm{p}<0.001)$. Thus, our study showed that there are no significant differences in the prevalence of most major cardiovascular risk factors in individuals with concomitant hypertension and autonomic dysfunction in groups distributed by level of blood pressure. This suggests that the fact of presence hypertension and dysautonomy has an independent clinical significance, and even with a mild increase in blood pressure, the patient is at high risk of acute vascular complications owing to a combination of negative factors.

Conclusions: Patients with moderate and severe hypertension and autonomic dysfunction don't have significant differences in the prevalence of most major cardiovascular risk factors (except smoking, $p=0.025$ ) compared to patients with mild hypertension. This indicates the importance of early detection of autonomic dysfunction, even with the initial increase in blood pressure.
\end{abstract}

KEY WORDS: hypertension, dysautonomia, cardiovascular risk

\section{APPLICATION OF INTERDISCIPLINARY APPROACH IN PREPARATION OF FUTURE MEDICAL SPECIALISTS FOR HEALTH PROMOTION}

\author{
Olha 0. Yezhova, Olha A. Sytnyk, Dmytro S. Voropaiev, Valentyna P. Buivalo
}

SUMY STATE UNIVERSITY, SUMY, UKRAINE

\begin{abstract}
Introduction: The leading public health strategies can be considered as defined in the report "A new respective on the health of Canadians" by the Minister of National Health and Welfare of Canada Marc Lalonde (1974). Among the other five strategies the following one has been recognized as leading: health promotion is a strategy to promote health through information dissemination, influence and assistance to both individuals and organizations, to build responsibility for the personal health and health of employees and incentives for action in the field of mental and physical health of the population. Training of health professionals to promote health among the population requires an interdisciplinary approach to the development of such disciplines.

Aim: The objective of the work is to substantiate the selection of the content of the academic discipline on health promotion based on an interdisciplinary approach.

Materials and methods: Theoretical methods of analysis and generalization of scientific literature, European practical experience in health promotion are used in the work; content analysis of the available online academic programmes of relevant disciplines for the specialities "Public Health" and "Physical therapy, occupational therapy".

Results: Given the essence of the definition of "health promotion" and the directions of this activity, it can be stated that the successful acquisition of skills in health promotion should be based on knowledge of biological and social (psychology and pedagogy) sciences. The basic biological sciences are studied during the first three years of study at the university, but psychology and pedagogy are not given enough attention. Therefore, the discipline of health promotion must contain the relevant knowledge and mould the skills necessary to cultivate responsibility for personal health and the health of others.
\end{abstract}

The best practices for the development of domestic university disciplines in health promotion contain three mandatory components: (1) theoretical; (2) pedagogical); (3) 
psychological. The theoretical one provides an acquaintance with the history of health promotion, the activities of the World Health Organization in health promotion, modern areas of health promotion in the world and Ukraine, successful global and European practices of health promotion. The pedagogical component includes knowledge of key pedagogical concepts "method", "methodology", "technology", "forms and means" and so on. While learning the pedagogical basics of health promotion, students master active and interactive teaching methods, training skills and various pedagogical tools and forms of educational activities to promote health. It should be noted that the psychological component of the discipline is becoming increasingly important in terms of significance and volume of educational material because for society the expected result of health promotion is a change in human behaviour, a formation of a healthy lifestyle. Thus, behavioural theories should be the basis of educational, preventive and information programmes. Therefore, students study theories of behaviour that are considered the most effective in health promotion: motivational, e.g. Health belief model (I. Rosenstock, 1974); The Theory of Planned Behaviour (I. Eisen, 1991); Protection motivation theory, (R. Rogers, 1975); Social learning theory (A. Bandura, 1989); models of interaction-communication, e.g. Information-Motivation-Behavioural Skills Model (Fisher \& Fisher, 1992-2000), the essence of which can be expressed by the triad "Know - Want - Learned"; staged ones, e.g. Stages of Change Model, (J. Prochaska and DiClemente, 1970).

Conclusions: Thus, it can be argued that the effectiveness of training of future medical professionals in health promotion depends on a harmonious combination of psychological and pedagogical basics and considering modern social realities in the content of the discipline, which corresponds to the principles of an interdisciplinary approach.

KEY WORDS: health promotion, interdisciplinary approach, behavioural theories, pedagogical methods, discipline of health promotion

\title{
LISTERIOSIS INFECTION AND ITS IMPACT ON PUBLIC HEALTH
}

\author{
Viktor O. Ziuzin, Liliia Ya. Muntian, Yurii A. Frolov, Olha V. Tuzova, Dmytryi V. Ziuzin, Yuryi D. Frenkel \\ PETRO MOHYLA BLACK SEA NATIONAL UNIVERSITY, MYKOLAYIV, UKRAINE
}

\begin{abstract}
Introduction: Listeriosis is an infectious disease that is a serious problem in human pathology. Listeriosis is characterized by a diverse clinical picture, the dominant lesion of persons with weakened resistance. First of all listeriosis affects pregnant women, newborns, young children, people with immunodeficiency, the elderly. Listeriosis is a ubiquitous infectious disease, hitherto little known and insufficiently studied. Listeria infection is one of the most important problems in epidemiological science and health in most developed countries. Currently in Ukraine there are no legislative acts on the need for mandatory registration of listeriosis, which does not allow to objectively assess its prevalence, epidemiological and clinical features, the level of social and economic damage caused by listeriosis infection. The selection of a number of current problems associated with this infection is possible only on the basis of further study of the ways of spread, the current potential of the pathogen, the epidemiological and microbiological characteristics of listeriosis.
\end{abstract}

Aim: Study of epidemiological clinical characteristics of modern listeriosis infection and a set of preventive and anti-epidemic measures.

Materials and methods: Epidemiological patterns of listeria prevalence in the environment and the incidence of listeriosis in the population of Ukraine. Epidemiological, clinical, serological, statistical methods of research of modern listeriosis infection.

Review: Listeriosis has been registered among people in Ukraine since 1992. Transmission of pathogenic listeria occurs through contaminated milk and dairy products, animal and poultry meat, vegetables, fish, seafood, eggs, mushrooms, confectionery, beverages. The clinical picture of listeriosis in humans is characterized by extreme polymorphism, affecting almost all organs and tissues of the body. In the development of the infectious process plays an important role not only its pathogen but also the state of the macroorganism. The entrance gates of infection are: mouth, intestines, tonsils, mucous membranes of the respiratory tract. Proper diagnosis of the disease is based on epidemiological data, clinical picture and laboratory tests, which are given leading importance. Prevention of listeriosis is to carry out veterinary and sanitary and hygienic measures in settlements, livestock farms and enterprises for processing products of animal origin. Considering that specific prevention of listeriosis in humans has not been developed, and the system of measures for epidemiological surveillance and prevention of listeriosis in Ukraine is under development, epidemiological surveillance for listeriosis should be specific in terms of composition and significance.

Conclusions: 1. The causative agent of listeriosis is actively circulating among the population and is found in the environment, food raw materials and food.

2. Carrying out epidemiological surveillance and prevention of listeriosis infection in modern conditions should be aimed at the implementation of bacteriological control of food raw materials and food products at risk of listeriosis infection and bacteriological examination of persons suspected of listeriosis, the implementation of approxation environment and clinical material.

3. The prevalence of listeriosis among patients with different clinical picture of the disease and the prevalence of listeria in the environment justifies the need for official registration of listeriosis infection among the population.

KEY WORDS: Epidemiology, clinical characteristics, prevention, measures. 


\title{
ULTRASOUND BIOMARKERS OF ATHEROSCLEROTIC PLAQUE IN PATIENTS WITH CAROTID ATHEROSCLEROSIS
}

\author{
Olga E. Dubenko ${ }^{1}$, Victoria Y. Anysienkova ${ }^{1}$, Olexander Y. Havryushin ${ }^{1,2}$, Olexander V. Zubkov ${ }^{2}$ \\ 'KHARKIV MEDICAL ACADEMY OF THE POSTGRADUATE EDUCATION, KHARKIV, UKRAINE \\ 2KHARKIV CITY CLINICAL HOSPITAL №7, KHARKIV, UKRAINE
}

\begin{abstract}
Introduction: Carotid atherosclerosis is the cause of 20-25\% of all cerebral ischemic strokes. Clinical, biochemical and ultrasound markers, neuroimaging plaque characteristics have been proposed as indicators of a high-risk plaque for stroke. Although risk of ischemic stroke are assessed according of degree of stenosis, qualitative characterization of plaques should be performed to detect vulnerable plaques. Ultrasonography it is now more accessible method and possible to identify high-risk plaques for clinical practice. Aim: To identify ultrasound feature of carotid plaque that associated with risk of stroke in patients with carotid atherosclerosis and different clinical presentation.

Materials and methods: The 106 patients with carotid atherosclerosis (74 men and 32 women, aged from 31 to 74 years (mean 62.6 \pm 0.9 ) were involved in the study. All patients divided on three groups: 35 patients (group 1) had presented with acute non-lacunar ischemic stroke in ipsilateral internal carotid artery (ICA) with stenosis degree $>50 \%, 41$ patients (group 2) who suffered from ischemic stroke and underwent carotid endarterectomy (CEA) on ipsilateral side, group 3 included 30 patients with stenosis of ICA and no history acute ischemic event (asymptomatic carotid stenosis). Neuroimaging was perform all patients. Carotid atherosclerotic examinations were performed with a high-resolution $(10.0 \mathrm{MHz})$ color Doppler ultrasound by scanner «MINDRAY DC-40». The degree of ICA stenosis was determine by the European Carotid Surgery Trial (ECST) method. Informed consent was obtained from all participants and the study approved by the local ethics committee.

Results: Proportion patients with high degree stenosis > 70\% was more in group 2 after CEA - in 63.4\%, in asymptomatic patients prevalence moderate stenosis 50-69\% - in 76.7\% $(\mathrm{p}=0.00023$ ). There was a statistically significant relationship between the degree of stenosis and the patient's gender in all patients. The proportion of women with stenosis from $50 \%$ to $69 \%$ significantly exceeds the proportion of men with a similar degree of stenosis $(\mathrm{p}=0.00300)$, and the proportion of men with 70-99\% stenosis is significantly higher than the same proportion of women ( $p=0.00492)$. We estimate of the following ultrasound characteristics of carotid plaques: heterogeneous echogenicity, surface irregularity, ulceration, plaques circulation and calcification. Soft homogenous plaques frequently detected in symptomatic patients with stenosis ICA- in 21 (27.6\%) compared with asymptomatic - 4 (13.3\%) ( $p=0.0062)$. Significant differences were seen between plaques calcification in symptomatic and asymptomatic stenosis ICA ( $p=0.0399)$. Significant differences were seen between plaques prolongation: in asymptomatic stenosis group observed predominantly local segmental plaques - in $23(76.7 \%)$, in symptomatic groups observed large prolong $(>1.5 \mathrm{~cm})$ - in 31 (40.78\%) and circulation - in 66 (86.84\%) plaques. Plaque surface irregularity did not seem to be related to the severity of stenosis as there was no statistically significant difference between symptomatic and asymptomatic groups $(\mathrm{p}=0.2086)$. However, while irregularly surfaced plaques are of equal frequency in symptomatic and asymptomatic stenosis, there was no ulceration in asymptomatic cases. Plaque echogenicity, plaque area, and plaque ulceration was defined as complex plaque and ultrasound markers of unstable plaques that increased stroke risk.

Conclusions: More plaques that are unstable were detect in symptomatic stenosis especially in group after CEA. Ultrasound evaluation of carotid artery stenosis should focus on the detection of these plaque characteristics in addition to quantifying the degree of stenosis. Carotid plaque assessment with ultrasonography provides superior risk stratification for individual patients.
\end{abstract}

KEY WORDS: atherosclerotic carotid stenosis, Doppler ultrasound, ischemic stroke.

\section{IMPACT OF CLINICAL FORMS OF PULMONARY TUBERCULOSIS ON THE EPIDEMIC SITUATION}

\author{
Igor D. Duzhyi, Halyna P. Oleshchenko, Ivan A. Hnatenko, Leonid A. Bondarenko, Polina O. Hornostaiieva \\ SUMY STATE UNIVERSITY, SUMY, UKRAINE
}

Introduction: Despite all scientists, health care providers, and government officials, tuberculosis's epidemic situation in Ukraine and the Sumy region is improving slowly. The morbidity of active tuberculosis (without relapses) for 12 months of 2019 compared to the same period in 2018 in Ukraine and Sumy region was 49,2 and 49,9 per 100 thousand populations and 50,5 and 55,1, accordingly ( $p>0,05$ ). The morbidity of children from 0 to 14 years increased from 8,9 to 9,0 per 100 thousand children in Ukraine and Sumy region - from 8,3 to 9,8. Besides, Ukraine is one of the world's five countries with the highest number of patients with multidrug-resistant pulmonary tuberculosis and tuberculosis with advanced drug resistance. Although WHO experts think that to stabilize the epidemic situation, it is necessary to achieve an indicator of «effective treatment» of at least 75,0\% of patients with MDR TB (WHO report, 2019), in Ukraine, this index does not reach 50,0\%. All the above determines the relevance of this problem.

Aim: The necessity of researching the relationship of different pulmonary tuberculosis forms on the development of contact (familial) tuberculosis is the aim.

Materials and methods: We researched 157 primary identified patients in focus initially detected pulmonary tuberculosis and 162 patients who were contacted persons that lived in this focuses of tuberculosis.

Results: Among those who were the source of tuberculosis infection, focal tuberculosis occurred in 5 people, and among contact - in 19, which is more, almost four times $(p<0,05)$, infiltrative tuberculosis occurred in 95 and 100 people, accordingly; disseminated tuberculosis in 44 and 20 people, consequently; fibro cavernous tuberculosis in 9 and 3 people. The increased number of diseases for extrapulmonary tuberculosis attracts attention ( $4-2,5 \%$ i $16-9,9 \%$ consequently). 
Conclusions: 1) The presence of a patient with tuberculosis in the family, which is not isolated, is a risk for the development of contact - «family» tuberculosis. 2) «Family» tuberculosis of focal and infiltrative tuberculosis prevails in contact persons. 3) More often (4 times), the process develops in the extrapulmonary organs.

KEY WORDS: family tuberculosis, forms of family tuberculosis, risks of developing family tuberculosis

\title{
ANALYSIS OF COVID-19 MORBIDITY LEVEL IN SUMY REGION IN 2020
}

\author{
Liudmyla I. Kiptenko, Andrey V. Horokh \\ DEPARTMENT OF MORPHOLOGY, SUMY STATE UNIVERSITY, MEDICAL INSTITUTE, SUMY, UKRAINE
}

Introduction: Currently, one of the main areas of medicine is focused on fight against COVID - 19, caused by coronavirus. Coronavirus infection is an acute viral disease caused by an RNA-containing virus of the genus Betacoronavirus of the Coronaviridae family, transmitted between animals and humans.

Aim: to show statistical analysis of the disease on COVID - 19 in Sumy region.

Materials and methods: analyzing results of PCR tests in Sumy region for period 2020 year. Based on the results of laboratory tests, a statistical analysis of the disease on COVID - 19 by region was carried out.

Results: Human coronaviruses (strain HCoV229E) were first isolated by D. Tyrrell and M. Bynoe in 1965 from patients with acute respiratory viral infections. Currently, they are divided into 4 subfamilies (alpha, beta, delta and gamma) and more than 30 species, the list of which is constantly replenished. The coronavirus genome is represented by single-stranded RNA with a length of about 30 thousand nucleotide units, which is the maximum size among all known RNA-containing viruses. The reason for the emergence of new coronaviruses, that cause severe and rapidly spreading diseases is spontaneous mutations. Therefore, all types of coronaviruses can potentially be dangerous for human. Pathogenesis of coronavirus infection: colonization and destruction by coronaviruses of upper respiratory tract epitheliocytes with further replacement of affected sections of alveoli walls with connective tissue.

We conducted an analysis, based on the statistical processing of disease data on COVID - 19 in the Sumy region for the period of 2020. During this time, 123181 studies using the PCR test method were carried out in the laboratories of the region.

Based on the results of PCR tests in the Sumy region in 2020, 40989 cases of coronavirus cases were confirmed. Among these patients, 34,513 people recovered, 529 - died. The largest number of patients was registered in Sumy - 19947 cases, which equals 48.7\% of all cases in region. In second place of the morbidity was in the town of Romny, where 1914 cases of the disease or 4.7\% were registered, and town of Konotop is last of the top three - 1882 cases registered, which equals $4.6 \%$. Among 18 districts of the region, the Sumy district is leading by index of morbidity, where 2,498 cases were documented. The smallest number of patients with COVID - 19 was registered in the Shostka district. The largest number of deaths was recorded in Sumy - 209, which equals $39.5 \%$ of all deaths in the Sumy region by COVID - 19 .

Considering the age aspect, the largest number of cases is noted in the age group of 18 to 65 years - 34127 people and the smallest number of cases in the age group from 0 to 17 years - 1512 people. In 2020, 25,000 women came down with COVID-19 in the Sumy region. Men that came down with virus were 9 thousand less in number - 15989 cases. Among all cases on COVID - 19, the disease of healthcare workers reached the index of 2,153 or $5.3 \%$ of all cases.

Conclusions: Overcrowded places cause faster spread of the infection. The consequences of the coronaviruses` mutation show that the transformations can lead to emergencies.

KEY WORDS: coronaviruses, statistical analysis, COVID - 19.

\section{ASSESSMENT OF BONE TISSUE MINERAL DENSITY IN WOMEN OF ALL AGES IN THE PRACTICE OF A FAMILY DOCTOR}

\author{
Yevheniia Y. Lukianets, Olga M. Barna, Yaroslava V. Korost \\ 0.0. BOHOMOLETS NATIONAL MEDICAL UNIVERSITY, KIYV, UKRAINE
}

\begin{abstract}
Introduction: 0steoporosis is the fourth most common after cardiovascular, cancer and endocrine diseases. According to WH0 experts, due to the aging population and the impact of negative environmental factors, the incidence of osteoporosis will increase further. Osteoporosis is known as the silent epidemic because it does not manifest until a fracture occurs. Despite advances in risk assessment and treatment, osteoporosis still often either not recognized or untreated.

Aim: Assess bone mineral density in women of different ages, analyze fracture risk factors among women with low-energy fractures.

Materials and methods: The study was based on a survey of women in major cities of Ukraine. 177 women aged 20 to 79 years were included. The average age of the subjects was $53 \pm 13.45$ years, the average body weight was $73 \pm 13.1 \mathrm{~kg}$, height $163.5 \pm 5.7 \mathrm{~cm}$, the average BMI was $27,38 \pm 5.10$. Normal body mass index (BMI) 20-24,9 had 63 women (35.6\%), rates of preobesity and clinical obesity were in 114 surveyed women (64.4\%). All patients were divided into age groups: young women $(n=22)-20-29$ years $(n=14), 30-39$ years $(n=8)$ and women over 40 years old (in pre and postmenopause) $(n=155)-40-49$ years $(n=42), 50-59$ years $(n=54), 60-69$ years $(n=38), 70-79$ years $(n=21)$. Also, women after the age of 40 were distributed according to the history of low-energy fractures. Ultrasound densitometry of the heel bone was used to assess the
\end{abstract}


structural and functional state of the bone tissue. The risk of fractures was determined using the Ukrainian model of the online calculator FRAX.

Results: As a result, among all examined women in terms of bone mineral density (BMD), regardless of age, 72 women (40.7\%) had normal BMD, osteopenia was found in 98 (55.4\%) and osteoporosis - 7 (3.9\%). Among young women, normal values have 14 women (mean age $28 \pm 3.89$ years, Z-index $-1.31 \pm 0.22$ ), osteopenia was found in 8 subjects $(27 \pm 6.08$, Z-index $0.02 \pm 0.55), p<0.01$. Among women after 40 years, statistically significantly lower BMD was in the age group $70-79$ years $-T$ index $-1.936 \pm$ $0.45(p<0.01)$. The risk of fractures and BMD by all algorithms was higher in women with fractures: FRAX Total $-14.17 \pm 5.27$ ( $p<0.01)$, FRAX Hip $-4.26 \pm 3.09$ ( $p<0.01$ ), FRAX Total with BMD - $10.91 \pm 4.74(p<0.01)$, FRAX Hip with BMD $-2.57 \pm 2.57(p<0.01)$, T-index $-1.56 \pm 0.66(p<0.001)$. The correlation analysis of BMD and the risk of fractures revealed a negative linear correlation of T-index with FRAX Total with BMD ( $r=-0.532, p<0.01)$, FRAX Hip with BMD $(r=-0.872, p<0.01)$, FRAX Total without $\operatorname{BMD}(r=-0.280, p<0.01)$, FRAX Hip without BMD $(r=-0.339, p<0.01)$ with age $(r=-0.273, p<0,01)$, a positive correlation with the $Z$-index $(r=0.790, p<0,001)$. No correlation was found with BMI $(\mathrm{p}>0.05)$.

Conclusions: Thus, BMD decreases with age. Women with a history of fractures have a significantly different risk of fractures and BMD than women without fractures. The risk of FRAX-total and FRAX-hip is significantly correlated with densitometry. With the help of the screening method, we were able to reach the population faster and on a larger scale. All of the above should be considered for planning preventive measures for osteoporosis and its complications, as well as for subsequent diagnostic steps for early detection of the disease.

KEY WORDS:0steoporosis, osteopenia, ultrasonic densitometry, risk factors of osteoporosis.

\title{
SPREAD OF HIV INFECTION IN SUMY REGION
}

\author{
Mykola P. Moskalenko, Valentyna M. Torianyk, Liudmyla P. Mironets, Anatolii P. Vakal \\ SUMY MAKARENKO STATE PEDAGOGICAL UNIVERSITY, SUMY, UKRAINE
}

Introduction: HIV appeared in Ukraine in the 1980s. During this time, the nature of the infection spread has changed significantly. In the beginning, drug injecting was the main mode of transmission. Later, starting from 2012, the Ukrainians have been getting infected through unprotected sex most times. In 2017, the part of such a mode was already $64 \%$ of all possible variants of HIV spread.

Aim: To investigate the patterns of HIV spread in Sumy region.

Materials and methods: Bibliosemantic, epidemiological, and statistical methods to analyze the existing statistical and other materials of health care institutions as for the spread of HIV among the population of Sumy region.

Results: HIV infection and related AIDS cases stay among the leading infectious diseases of the population of Sumy region. Despite the fact, that the overall infection rate is much lower than the national average one, the intensity of the HIV epidemic process but still is slowly increasing. According to the material of dispensary observation, the prevalence of HIV infection in the region is 137.7 cases per 100,000 population (Ukraine - 329.6 cases). Consequently, the prevalence rate for AIDS is 41.7 cases per 100,000 population (Ukraine - 100.9 cases). Over the last 20 years, 2,957 cases of HIV infection have been registered in Sumy region, as well as 942 cases of AIDS and 261 deaths from comorbidities. The first diagnosis of HIV infection in the region was made in 1987. From 1988 to 1995, no cases of the disease were recorded in Sumy region. From 1996 to 2008 , the HIV infection rate increased from 0.76 to 16.3 cases per 100,000 population. During the period from 2008 to 2020 , two minor morbidity spikes took place. First, there was an increase from 16.3 cases in 2008 to 18.5 cases per 100,000 population in 2010, and then a decrease to 14.8 in 2012 per 100,000 population. The second spike lasted from 2013 to 2017, when the prevalence rate was balancing from 17.9 to 19.8 per 100,000 population. In 2016, 18.5 cases were recorded in Sumy region, in 2017 this number rose to 19.8 cases per 100,000 population. In the same year in Ukraine, it was 37.8 per 100,000 population. The decrease of the HIV infection prevalence in Ukraine in 2014 and 2015 happened as there were no statistics from the Autonomous Republic of Crimea and some territories of Donetsk and Luhansk regions. In the following years, the rate of HIV infection in Sumy region has being fluctuated at the level of 21-22 cases per 100,000 population.

According to the medical records, in 2020, among the HIV-infected people who were under the regular medical check-up, there was the following sex ratio: $47 \%$ of women, $53 \%$ of men. Among the people diagnosed with AIDS, there were $34.6 \%$ of women and $65.4 \%$ of men. The distribution of urban and rural dwellers among HIV-infected patients is as follows: $75.3 \%$ - the first group, $24.7 \%$ - the second one; concerning AIDS, $77.6 \%$ and $22.4 \%$ respectively. In recent years, people aged $25-49$ prevailed in the age structure of newly registered HIV-infected patients. In 2019, this age category made up $70.2 \%$, including $72.7 \%$ among men and $66.7 \%$ among women. The share of people in their 50 s and older also tended to grow, in 2019 it was $9.2 \%$. In this age category, men dominate with the share of $70 \%$.

Conclusions: The epidemic situation of HIV infection in Sumy region is to be regarded as stable in comparison with other regions of Ukraine. In recent years, in our region, the prevalence of HIV is captured 2.40 times and of AIDS 2.43 times less than in Ukraine. Each year in the 21st century, the HIV incidence in Sumy region has been almost twice as low as the national one.

KEY WORDS: epidemic, diseases, health care, AIDS. 


\title{
GENDER AND AGE FEATURES OF «FAMILIAL» TUBERCULOSIS IN THE SUMY REGION
}

\author{
Halyna P. Oleshchenko, Igor D. Duzhyi, Oleksandr M. Lytvynenko, Vasyl P. Melnyk, Leonid A. Bondarenko, \\ Ivan A. Hnatenko \\ SUMY STATE UNIVERSITY, SUMY, UKRAINE
}

Introduction: It is known that tuberculosis infection occurs during a prolonged stay in close contact with the patient indoors. Among other common ways of contact is the so-called «family». In the context of the Covid-19 epidemic and the reform of the tuberculosis service in Ukraine, when migration is declining, and the vast majority of bacillary patients are treated on an outpatient basis, the spread of tuberculosis infection in the family is particularly acute, which determines the urgency of the problem. Aim: The purpose of this study was to determine the gender and age characteristics of «familial» tuberculosis.

Materials and methods: The medical documentation of tuberculosis patients who had family contact during 2006-2018 in the Sumy region was retrospectively analyzed. The source of infection was 157 patients with various forms of tuberculosis. It has been reliably confirmed that these patients caused the disease in 162 contact persons. That is, one patient was involved in the disease with more than one family member.

Results: Among the patients - «sources» of tuberculosis infection were 127 (80.9\%) males and 30 (19.1\%) females. Among the «contactors» there were 78 males (48.1\%) and females $-84(51.9 \%)-(p<0.05)$. Thus, women are significantly more likely to get sick due to home contact with sick men. According to age, the «sources» of tuberculosis infection are distributed as follows. At the age of 0-18 years there was $1(0.6 \%)$ patient, 19-28 years - 18 (11.5\%) persons, at the age of $29-38$ years there were 50 (31.8\%) patients, 39-48 years $-49(31.2 \%)$, aged 49-58 years $-26(16.6 \%)$, older than 59 years $-13(8.3 \%)$. Thus, the main group of infection sources (79.6\%) were persons aged 29-56 years. The mean age of patients involved in the disease of family members is $42.5 \pm 2.4$ years. Among those infected with these sources of tuberculosis were 41 (25.3\%) children under the age of 18 , young people aged 19-28 were registered 32 (19.7\%), aged 29-38 were 44 (27,3\%) persons aged 39-48 years - 19 (11.7\%) patients, 49-58 years $-14(8.6 \%)$, over 59 years $-12(7.4 \%)$ persons. The vast majority (72.2\%) of family members were young people under 40 years of age. Moreover, most importantly, a quarter (25.3\%) of the patients were CHILDREN! The mean age of «contact» persons was $31.6 \pm 1.9$ years $(p<0.05)$.

Conclusions: Thus, in our study, a «typical» example of tuberculosis sources was males aged $42.5 \pm 2.4$ years. It can be explained by a tendency to smoke and abuse alcohol, which provokes antisocial behavior and low adherence to treatment. The latter contributed to the infection in the vast majority of women and children. Thus, «reforming medicine» by eliminating and reducing the network of anti-tuberculosis hospitals and dispensaries, where such patients would be treated, at least until the cessation of bacterial excretion, and the network of anti-tuberculosis children's sanatoriums, where children could recover and be isolated from sick adults. , premature.

KEY WORDS: «familial» tuberculosis, contact person, source of infection.

\section{ESTABLISHMENT OF ELECTRONIC INFORMATION AND COMMUNICATION SYSTEM FOR HEALTH CARE QUALITY OPTIMIZATION IN PATIENTS WITH DIABETES OF 2 TYPE}

\author{
Vladyslav A. Smiianov' ${ }^{1}$ Alla V. Stepanenko², Nataliia 0. Dryha' ${ }^{1}$ \\ 'SUMY STATE UNIVERSITY, SUMY, UKRAINE \\ 2UKRAINIAN MILITARY MEDICAL ACADEMY, KYIV, UKRAINE
}

\begin{abstract}
Introduction: Optimization of quality of health care (HCQ) for patients with diabetes (DM) is a dynamic process during which requirements of society for high-quality medical care (MC) have to be satisfied and improve quality of life of patients. Achievement of significant progress in treatment of patients is possible under the conditions of creation and ensuring appropriate functioning of a system of prevention, diagnostics and treatment; wide acceptance of modern medical technologies, introduction of standards of delivery of health care into the practical activities. It should be noted that maintaining health is not only a medical, but also social problem and depends on responsibility of the patient for his or her health state. Therefore, an introduction of the modern information and communication system (ICS) for active involvement of the patient to process of treatment and prevention of complications of chronic non-communicable diseases (CNCDs), including DM 2 type, and a constant reminder to patients about importance of control of the main physical data, observance of a healthy lifestyle and mode of treatment, is relevant.

Aim: assessment of ICS effectiveness implementation for HCQ optimization in patients with DM of 2 type at the level of primary medical care establishment (PMCE) in Sumy. Materials and methods: methods, used in a study included interviewing with a specially created closed questionary, that took place from December 2019 till January 2020. During the study, systematic, bibliosemantic, comparative, statistical and inference techniques were used.

Results: The study group included 96 respondents: women - 58 (60.42 $\pm 3.53 \%)$; men - 38 (39.58 $\pm 3.53 \%)$. In this group, a dynamic two-way observation and treatment algorithm using the information and communication system (ICS) «Remote medical service in the system of quality management of medical care at the primary level» was introduced for six months. Analysis of the results of re-monitoring showed that during the period of implementation of the ICS, the indicators of HCQ and the state
\end{abstract}


of health of respondents has improved. The proportion of patients who indicated that they control the level of glycemia every day increased by $22.91 \%$ (before the introduction of ICS the rate equaled $8.33 \pm 1.99 \%$, after the implementation $-20.83 \pm 2.93 \%$ ), and index of those who control the level of glucose twice a day increased by $8.33 \%$ (before the implementation of ICS $-16.67 \pm 2.69 \%$, after the implementation - 39,58 $33,53 \%$ ). Also, the proportion of patients who control their blood pressure (BP) every day increased by $32.29 \%$ (before the introduction of ICS the rate equaled $43.75 \pm 5.06 \%$, after implementation $-76.04 \pm 4.36 \%$ ). At the time of the survey, there was a $24.47 \%$ increasing in the proportion of patients with a target BP level (before the introduction of ICS- $21.88 \pm 2.98 \%$, after the implementation - $46.35 \pm 3.60 \%$ ) and a $21.88 \%$ increasing in the rate of patients with a satisfactory level of compensation for type $2 \mathrm{DM}$ (before the implementation of ICS- $45.83 \pm 3.60 \%$, after the

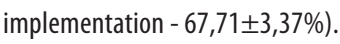

Conclusions: The introduction of ICS and feedback between service consumer and healthcare provider at the PMCE level showed a positive effect on the involvement of patients in dynamic control of their health status, on the attitude and awareness of patients of the importance of preventing risk factors for the development of CNCDs and their complications.

KEY WORDS: Primary Medical Care, prevention of non-infectious diseases, e-Health, self-control.

\title{
CLINICAL FEATURES OF THE BECK`S SARCOIDOSIS
}

\author{
Oksana V. Veremiienko', Kateryna A. Krasovska², Victoria A. Savoskina ${ }^{2}$ \\ 'KHARKIV NATIONAL MEDICAL UNIVERSITY, DEPARTMENT OF PROPAEDEUTIC OF INTERNAL MEDICINE No 2 AND NURSING, KHARKIV, UKRAINE \\ ${ }^{2}$ KHARKIV MEDICAL ACADEMY OF POSTGRADUATE EDUCATION, KHARKIV, UKRAINE
}

Introduction: Sarcoidosis (Benier - Schaumann - Beck disease) is a systemic disease with the development of epithelioid cell granulomas that affects many organs and systems, but most often the lungs, bronchi, and intrathoracic lymph nodes are involved in the process.

Nowadays, sarcoidosis continues to be a common disease that occurs in all countries around the world, affecting people of any race, gender and age. The highest incidence of sarcoidosis is observed among the urban population, especially in large industrial cities with air pollution from industrial waste. The spread of the sarcoidosis process by the lymphohematogenous route leads to damage many organs (skin, heart, kidneys, liver, spleen, eyes, endocrine system, central nervous system, peripheral lymph nodes).

Aim: to determine the features of the clinical course and the activity of the sarcoidosis process.

Materials and methods: Along with traditional clinical studies (clinical blood test, clinical urine test, sputum examination, biochemical blood test), studies were carried out to identify the activity of the sarcoidosis process. For this, the following methods were used: determination of angiotensin-converting enzyme (ACE), C-reactive protein, determination of $\mathrm{Ca}$ and $\mathrm{P}$ in blood and urine, IgG due to cytomegalovirus, Epstein-Barrvirus, herpes simplex virus type 1.2, tuberculin test was also studied. To verify the diagnosis, radiation diagnostics of the chest was carried out: X-ray, CT scan of the chest, MRI, ultrasound examination of the lymphnodes.

Results: We examined 16 patients with sarcoidosis of the intrathoracic lymphnodes and lesions of the organs of the chest, skin, heart. There were 10 men and 6 women, whose age ranged from 25 to 63 years old, averaging 49 years old; The most common and only complaint was dyspnae. 8 patients were observed by dermatologists in connection with skin lesions, they were identified and confirmed cutaneous forms, chills of Benier-Tennyson, Lefgren's syndrome. One patient was diagnosed with cardiac sarcoidosis, along with involvement of the retrosternal lymph nodes.

The course of the disease was diagnosed at various stages. In 3 patients, sarcoidosis was identified by random X-ray examination. According to the results of the examination, an enlargement of paratracheal, paraaortic and bifurcational lymphnodes was revealed.

In the study of blood in 6 patients, lymphopenia was found - $12 \pm 5.3 \%$, monocytosis $15.0 \pm 7.20 \%$, an increase of ESR up to $30 \mathrm{~mm}$ per hour was noted in all patients. The calcium content in the blood is $2.55 \pm 0.26 \mathrm{mmol} / \mathrm{L}$ (normal $2.25-2.75 \mathrm{mmol} / \mathrm{L}$ ), the calcium in the urine is $8.50 \pm 1.70 \mathrm{mmol} /$ day (normal $2.5-7.5 \mathrm{mmol} /$ day), the phosphorus content in the blood averaged $1.85 \pm 0.64 \mathrm{mmol} / \mathrm{L}$ (normal 0.87-1.45 mmol / L), phosphorusintheurinewas $35.70 \pm 3.40 \mathrm{mmol} /$ day (normal $42.00 \mathrm{mmol} / \mathrm{day}$ ), C-reactiveproteinwasincreasedin 7 patients andamountedto $9.0 \pm 3.5 \mathrm{mg} / \mathrm{dl}$ (normal $5.0 \mathrm{mg} / \mathrm{dl}$ ). Hypercalciuria occurred in $25 \%$ of patients.

Conclusions: Thus, observing patients with sarcoidosis, we found the absence of specific complaints, a combination of lung pathology with pathology of other organs and systems, and the absence of certain characteristic patterns. Along with lymphadenopathy of the retrosternal lymphnodes, leukocytosis with a shift to the left, lymphopenia with monocytosis, increased increased C-reactive protein, calciuria, with a greater degree of probability, can be signs of an exacerbation of the disease.

KEY WORDS: sarcoidosis, C-reactive protein, lymphadenopathy. 